\title{
The Protection Potential of Antioxidant Vitamins Against Acute Respiratory Distress Syndrome: a Rat Trial
}

\author{
Nazli Erol, ${ }^{1}$ Leyla Saglam, ${ }^{2}$ Yavuz Selim Saglam, ${ }^{3}$ Huseyin Serkan Erol $@,{ }^{4,7}$ Serdar Altun, ${ }^{3}$ \\ Mustafa Sinan Aktas, ${ }^{5}$ and Mesut Bunyami Halici ${ }^{6}$
}

\begin{abstract}
Acute respiratory distress syndrome (ARDS) is a fatal disease that includes inflammation formed by septic and non-septic causes. Reactive oxygen radicals (ROS) play a key role in ARDS pathophysiology and constitute the base of damage process. Antioxidant vitamins are used for inhibiting hazardous effects of radicals. Therefore, effects of antioxidant vitamins such as $\alpha$-lipoic acid (ALA), vitamin E (VITE), and C (VITC) were investigated on oleic acid (OA)-induced ARDS rat model. Furthermore, high and low dose of methylprednisolone (HDMP, LDMP) was used for comparing effects of the vitamins. In this study, 42 male rats were divided to seven groups named control, OA, ALA, VITE, VITC, LDMP, and HDMP. OA was intravenously administered to all groups except control group and other compounds were orally administered (ALA, VITE, and VITC: $100 \mathrm{mg} / \mathrm{kg}$, LDMP: $5 \mathrm{mg} / \mathrm{kg}$, HDMP: $50 \mathrm{mg} / \mathrm{kg}$ ) after OA injections. OA increased MDA level in lung tissue and TNF- $\alpha$ and IL- $1 \beta$ cytokine levels in serum. ALA, VITE, VITC, and both dose of MP significantly decreased the cytokine levels. Although OA reduced SOD, CAT, and GSH levels in lung tissue, the vitamins and LDMP markedly enhanced the levels except for HDMP. Furthermore, OA showed thickening in bronchi and alveolar septum, hyperemia in vessels, and inflammatory cell infiltrations in lung tissue histopathological examinations. Antioxidant vitamins may be useful for premedication of ARDS and similar disorders. However, methylprednisolone was not found sufficient for being a therapeutic agent for ARDS.
\end{abstract}

KEY WORDS: alpha-lipoic acid; ARDS; vitamin C; vitamin E; oleic acid; rat.

\footnotetext{
${ }^{1}$ Kastamonu State Hospital, Department of Chest Disease, 37200 Kastamonu, Turkey

${ }^{2}$ Faculty of Medicine, Department of Chest Disease, Ataturk University, 25100 Erzurum, Turkey

${ }^{3}$ Faculty of Veterinary Medicine, Department of Pathology, Ataturk University, 25100 Erzurum, Turkey

${ }^{4}$ Faculty of Veterinary Medicine, Department of Biochemistry, Kastamonu University, 37200 Kastamonu, Turkey

${ }^{5}$ Faculty of Veterinary Medicine, Department of Internal Medicine, Ataturk University, 25100 Erzurum, Turkey

${ }^{6}$ Faculty of Veterinary Medicine, Department of Biochemistry, Ataturk University, 25100 Erzurum, Turkey

${ }^{7}$ To whom correspondence should be addressed at Faculty of Veterinary Medicine, Department of Biochemistry, Kastamonu University, 37200 Kastamonu, Turkey. E-mail: hserol@kastamonu.edu.tr
}

\section{INTRODUCTION}

Acute respiratory distress syndrome (ARDS) is a fatal inflammation process described as acute diffuse lung inflammation and commonly generated by sepsis, trauma, pneumonia, burns, multi-organ transplantation, cardiopulmonary operations, and pancreatitis [12]. This fatal inflammation process leads to degradation of pulmonary vascular 
permeability and lung damages such as edema, hyaline membrane, and hemorrhage [16]. Patients with ARDS need critical treatments such as intensive care, mechanic ventilator, drugs, and long-period patient follow-up [19]. The inflammation process in ARDS is activated after releasing of inflammatory mediators from pulmonary endothelium, macrophage, and neutrophil cells. Microvascular barriers of lung alveolar tissue are disrupted and inflammation cells accumulate in lung tissue from vessels. The hyaline membrane occurs after inflammation cell accumulation and makes difficult oxygen transfer from alveolar tissue to vessels [23].

Reactive oxygen species (ROS) are mostly formed by stress conditions in inflammation, diseases, unsuitable heat conditions, long-term exercises, etc. The imbalance of oxygen transfer causes ROS burst in lung tissue. Moreover, formation and accumulation of ROS are enhanced by inflammation process that leads to oxidative stress in tissues. ROS mainly prefer to attack lipids. Unsaturated kinds have priority among all lipids and cell membranes are abundant in unsaturated lipids. The cell membrane damage causes disruption of lung tissue integrity [18]. Therefore, the ROS constitute the basis of the tissue damage.

Vitamins are commonly used by cells as a component of the structure, the activator of metabolic reactions, coenzyme, and defense against the ROS. Since the beginning to be understood antioxidant defense system, the effects of the vitamins on ROS have been deeply investigated. Especially vitamin $\mathrm{C}$ and $\mathrm{E}$ have been performed on the oxidative stress and the findings showed that these vitamins have some specific protective effects such as scavenging the radicals [2], activating antioxidant enzymes (superoxide dismutase, catalase etc.) [11], regenerating the antioxidant structures (glutathione) [7], and breaking the oxidative reaction chains of lipids [28].

The vitamins have been tried as a treatment on many disease models in laboratory animals [27]. In present study, the effects of antioxidant vitamins such as $\alpha$-lipoic acid (ALA), vitamin C (VITC), and E (VITE) were examined on oleic acid-induced acute lung injury in rats and compared with methylprednisolone (MP).

\section{MATERIAL AND METHODS}

Ethical approval for this study was obtained from Ataturk University Animal Experiments Local Ethics Committee (Reg. No: 36643897-147, Session/Decision number: 2/38). The ad libitum water and standard rat feed (Bayramoglu Animal Feed Inc., Turkey) (Table 1) were given rats kept in normal conditions $(12 / 24 \mathrm{~h}$ light cycle, $24{ }^{\circ} \mathrm{C}$ room temperature, and $40-60 \%$ humidity). The experimental animal ARDS model was performed by oleic acid (OA) and designed with 120-day-old 42 "Sprague dawley" male rats weighed between 240 and $260 \mathrm{~g}$. Rats divided to seven groups named as control (healthy, $n=6$ ), OA (oleic acid, $n=6$ ), ALA ( $\alpha$-lipoic acid, $n=6$ ), VITC (vitamin C, $n=6$ ), VITE (vitamin E, $n=6$ ), LDMP (lowdose methyl prednisolone, $n=6$ ), and HDMP (high-dose methyl prednisolone, $n=6$ ). The $\alpha$-lipoic acid (Solgar $®$, USA), vitamin C, and E (Sigma-Aldrich, USA) were in crystalline form and solved in distilled water. Methylprednisolone (Prednol®, Mustafa Nevzat, Turkey) was in powder form and solved in saline solution. Respectively, $100 \mathrm{mg} / \mathrm{kg} \alpha$-lipoic acid, $100 \mathrm{mg} / \mathrm{kg}$ ascorbic acid, and $100 \mathrm{mg} / \mathrm{kg} \alpha$-tocopherol were administered to the groups one time orally by using a rat gavage probe and $5 \mathrm{mg} / \mathrm{kg}$ and $50 \mathrm{mg} / \mathrm{kg}$ methylprednisolone were intraperitoneally administered to LDMP and HDMP groups one time by using insulin injectors. The $50 \mu \mathrm{L}$ OA solved in $250-\mu \mathrm{L}$ $1 \%$ BSA intravenously administered to all groups except the healthy group immediately after administrations of treatments. The rats were euthanized by cervical dislocation. The lung tissues and blood samples were obtained and used for biochemical and histopathological investigations.

\section{Biochemical Analysis}

All chemicals were provided from Sigma-Aldrich Inc., USA, and all solutions were freshly prepared in experiment day.

\section{Determining of Lipid Peroxidation Levels}

Lipid peroxidation (LPO) levels of tissues were measured by determining malondialdehyde (MDA) via the thiobarbituric acid reaction [29]. The tissues were weighed (Denver Instrument, USA) as $100 \mathrm{mg}$ and homogenized (Qiagen Tissuelyser LT, USA) in $10 \mathrm{~mL}$ of $10 \% \mathrm{KCl}$ solution. Measurement solution contains $1.5 \mathrm{~mL}$ of $8 \mathrm{~g} / \mathrm{L}$ 2-thiobarbiturate, $0.2 \mathrm{~mL}$ of $80 \mathrm{~g} / \mathrm{L}$ sodium lauryl sulfate, $1.5 \mathrm{~mL}$ of $200 \mathrm{~g} / \mathrm{L}$ acetic acid, and $0.3 \mathrm{~mL}$ of distilled water in sterile tubes. Then, $0.5 \mathrm{~mL}$ of homogenate added mixtures was incubated at $98{ }^{\circ} \mathrm{C}$ for $1 \mathrm{~h}$. Five milliliters of nbutanol/pyridine (15:1) was added after incubation. The mixture tubes were shaken for $60 \mathrm{~s}$ and centrifuged for half an hour at $4000 \mathrm{rpm}$. The supernatants were collected and measured at $532 \mathrm{~nm}$ in a spectrophotometer. The LPO standard graphic was prepared by using 1,1,3,3-tetramethoxypropane. The results were calculated according to standard graphic and expressed as nmol MDA/g tissue. 
Table 1. Feed Composition of Rat Diets

\begin{tabular}{|c|c|c|c|}
\hline \multicolumn{4}{|l|}{ Composition of rat diets } \\
\hline \multicolumn{3}{|l|}{ Protein } & $27 \%$ \\
\hline \multicolumn{3}{|l|}{ Carbohydrates } & $53 \%$ \\
\hline \multicolumn{3}{|c|}{ Fat (includes essential fatty acids) } & $3 \%$ \\
\hline \multicolumn{3}{|c|}{ Others (water, vitamins, minerals, and cinders) } & $17 \%$ \\
\hline \multicolumn{3}{|c|}{ Calories } & $3.6 \mathrm{kcal} / \mathrm{g}$ \\
\hline \multicolumn{4}{|c|}{ Vitamin and mineral composition of rat feed } \\
\hline Vitamin A & $18.000 \mathrm{IU} / \mathrm{kg}$ & D-Biotin & $0.06 \mathrm{mg} / \mathrm{kg}$ \\
\hline Vitamin D3 & $2.400 \mathrm{IU} / \mathrm{kg}$ & Choline chloride & $480 \mathrm{mg} / \mathrm{kg}$ \\
\hline Vitamin K3 & $6 \mathrm{mg} / \mathrm{kg}$ & Manganese & $96 \mathrm{mg} / \mathrm{kg}$ \\
\hline Vitamin B1 & $3.6 \mathrm{mg} / \mathrm{kg}$ & Iron & $48 \mathrm{mg} / \mathrm{kg}$ \\
\hline Vitamin B2 & $9 \mathrm{mg} / \mathrm{kg}$ & Zinc & $72 \mathrm{mg} / \mathrm{kg}$ \\
\hline Vitamin B6 & $6 \mathrm{mg} / \mathrm{kg}$ & Cupper & $6 \mathrm{mg} / \mathrm{kg}$ \\
\hline Vitamin B12 & $0.024 \mathrm{mg} / \mathrm{kg}$ & Iodine & $2.4 \mathrm{mg} / \mathrm{kg}$ \\
\hline Niacin & $30 \mathrm{mg} / \mathrm{kg}$ & Cobalt & $0.6 \mathrm{mg} / \mathrm{kg}$ \\
\hline Calcium-D-Panthenol & $12 \mathrm{mg} / \mathrm{kg}$ & Selenium & $0.18 \mathrm{mg} / \mathrm{kg}$ \\
\hline Folic acid & $1.2 \mathrm{mg} / \mathrm{kg}$ & & \\
\hline
\end{tabular}

\section{Determining of Superoxide Dismutase Enzyme Activity}

The enzyme activity was measured by determining formazan reaction [34]. The assay method bases on various reactions that generate formazan from nitro blue tetrazolium (NBT) by producing the superoxide radicals during xanthine oxidase activity. The lung tissues were homogenized in $0.2 \mathrm{mM}$ Tris- $\mathrm{HCl}$ solution ( $\mathrm{pH} 7.4$ ) and added on measurement solution that were containing $150 \mu \mathrm{M}$ NBT, 0.6 mM EDTA, $0.3 \mathrm{mM}$ xanthine, $0.4 \mathrm{M} \mathrm{Na}_{2} \mathrm{CO}_{3}, 1 \mathrm{~g} / \mathrm{L}$ BSA. Xanthine oxidase (167 U/L) enzyme solution was prepared in cold $2 \mathrm{M}\left(\mathrm{NH}_{4}\right)_{2} \mathrm{SO}_{4}$, then added on samples. The $0.8 \mathrm{mM} \mathrm{CuCl}_{2}$ was used for stopping the reaction after 20 min from addition of enzyme solution. SOD activity was expressed as $\mathrm{mmol} / \mathrm{min} / \mathrm{mg}$ tissue after measuring at $560 \mathrm{~nm}$.

\section{Determining of Catalase Enzyme Activity}

Catalase (CAT) catalyzes a reaction that is decomposition of $\mathrm{H}_{2} \mathrm{O}_{2}$ that measured at $240 \mathrm{~nm}$ [1]. The tissues homogenized in $50 \mathrm{mM} \mathrm{KH}_{2} \mathrm{PO}_{4}$ buffer $(\mathrm{pH} 7)$ and $30 \mathrm{mM}$ $\mathrm{H}_{2} \mathrm{O}_{2}$ were prepared for measurement. The CAT activity was expressed as $\mathrm{mmol} / \mathrm{min} / \mathrm{mg}$ tissue and defined as the amount of enzyme required to decompose $1 \mathrm{mmol}$ of hydrogen peroxide per minute at $\mathrm{pH} 7$ and $25^{\circ} \mathrm{C}$.

\section{Determining of Total Glutathione Levels}

Glutathione (GSH) levels of lung tissues were determined according to the method described by Sedlak and Lindsay (1968) [32]. The tissues were homogenized in
$50 \mathrm{mM}$ Tris buffer (pH 7.4) that contains 20 mM EDTA. Homogenates were centrifuged at $3000 \mathrm{~g}$ for $40 \mathrm{~min}$ at $4{ }^{\circ} \mathrm{C}$. The supernatant was collected and added in a mea-

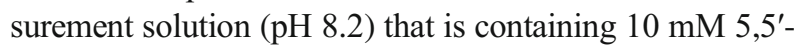
dithiobis (2-nitrobenzoic acid) (DTNB), $200 \mathrm{mM}$ Tris, and $0.2 \mathrm{mM}$ EDTA. GSH levels of the tissues were determined at $412 \mathrm{~nm}$ and expressed as $\mathrm{nmol} / \mathrm{mg}$ tissue.

\section{Determining of Serum Tumor Necrosis Factor Alpha and Interleukin 1 Beta Levels}

Blood was collected into a serum tube that contains polymer gel (BD RSTTM, USA) and centrifuged for $7 \mathrm{~min}$ at $3500 \mathrm{rpm}$. Serum was taken into a 2-mL Eppendorf tube. TNF- $\alpha$ (Invitrogen Novex ${ }^{\circledR}$ TNF- $\alpha$ Elisa Kit Cat. No: KRC3011, USA) and IL-1 $\beta$ (Invitrogen Novex ${ }^{\circledR}$ IL-1 $\beta$ Elisa Kit Cat. No: KRC0011, USA) were estimated by using sandwich ELISA kits. Cytokines were measured in accordance with the procedures of kits. The values were calculated from a generated graph by using presented standards in kits.

\section{Histopathological Examination}

Samples were fixed for histopathological evaluations by stored for $24 \mathrm{~h}$ in a $10 \%$ buffered formalin solution. After the routine histopathology process (Tissue System, Shandon Citadel 2000,USA), lung tissues were poured into paraffin for blocking. Microtome sections were prepared as $5 \mu \mathrm{m}$ by using rotary microtome (Leica RM 2255). All sections were stained with Hematoxylin-Eosin (H\&E) and 
examined under the light microscopy (Olympus BX51 with DP72 camera attachment). Semi-quantitative scoring under light microscope was used in consideration of the following criteria: thickening in the interalveolar septum, peribronchial cell infiltration, and hyperemia in vessels. Each parameter was scored as "-” (none), “+” (slight), "++" (moderate), and "+++" (severe) points (Table 2).

\section{Statistical Analyses}

The IBM SPSS 20 software program was used to perform the statistical analyses. All values were shown as the mean \pm standard error mean (SEM). Significant differences were determined after the data were analyzed by Duncan's multiple range test.

\section{RESULTS}

\section{Biochemical Analyses}

LPO and GSH levels as well as SOD and CAT activities in lung tissue are summarized in Fig. 1. The LPO level in OA group significantly increased compared with control group $(P<0.05)$ (Fig. 1a). Otherwise, ALA, VITE, VITC, LDMP, and HDMP markedly decreased the LPO levels compared with OA group $(P<0.05)$. There was no significant statistical difference between control and ALA group $(P>0.05)$. The SOD activity in OA group markedly decreased compared with control group $(P<0.05)$ (Fig. 1b). ALA, VITE, VITC, and LDMP significantly increased SOD activity compared with OA group $(P<0.05)$. However, there was no significant statistical difference between HDMP and OA groups $(P>0.05)$. Total GSH level in OA group significantly decreased compared with control group $(P<0.05)$ (Fig. 1c). ALA, VITE, and VITC significantly elevated GSH level compared with OA group $(P<0.05)$. On the other hand, GSH level in LDMP group was measured low than OA group $(P<0.05)$ and there was no significant statistical difference between HDMP and OA groups $(P>0.05)$. The CAT activity in OA group markedly decreased compared with control group $(P<0.05)$ (Fig. 1d). ALA, VITE, and VITC elevated CAT activity compared with OA group $(P<0.05)$. Besides, there were no significant statistical differences in CAT activities of LDMP and HDMP groups compared with OA group $(P>0.05)$.

Serum TNF- $\alpha$ and IL-1 $\beta$ levels are shown in Fig. 2. The serum TNF- $\alpha$ level in OA group significantly increased compared with control group $(P<0.05)$ (Fig. 2a). There were no significant statistical differences between ALA, VITE, VITC, and HDMP groups $(P>0.05)$. The serum IL-1 $\beta$ level in OA group markedly increased compared with control group $(P<0.05)$ and ALA, VITE, VITC, LDMP, and HDMP decreased significantly the level $(P<0.05)$ (Fig. 2b). There were no significant statistical differences between ALA, VITE, VITC, LDMP, and HDMP groups $(P>0.05)$.

\section{Histopathological Examination}

The normal structure was observed in control group lung tissues (Fig. 3a, Table 2). Severe thickening in the interalveolar septum, peribronchial cell infiltration, hyperemia in vessels were watched in OA group lung tissues (Fig. 3b, c, Table 2). In ALA group, lung tissues showed slight proliferation in interstitial areas and moderate hyperemia in vessels (Fig. 3d, Table 2). In VITE groups, lung tissue examination, moderate peribronchial mononuclear cell infiltration, moderate thickening in interalveolar, and interlobular septum were observed (Fig. 3e, Table 2). Slight proliferation in interalveolar septum, slight peribronchial mononuclear cell infiltration, and moderate hyperemia in vessels were shown in VITC group (Fig. 3f, Table 2). Moderate mononuclear cell infiltration in

Table 2. The histopathologic findings of lung tissues

\begin{tabular}{llll}
\hline & Thickening in the interalveolar septum & Peribronchial cell infiltration & Hyperemia in vessels \\
\hline Control & - & - & - \\
OA & +++ & +++ & +++ \\
ALA & + & + & ++ \\
VITE & ++ & ++ & +++ \\
VITC & + & + & ++ \\
LDMP & ++ & ++ & ++ \\
HDMP & +++ & +++ & +++ \\
\hline
\end{tabular}

The histopathological scores of lung tissues were defined as none (-), slight (+), moderate (++), and severe (+++) 

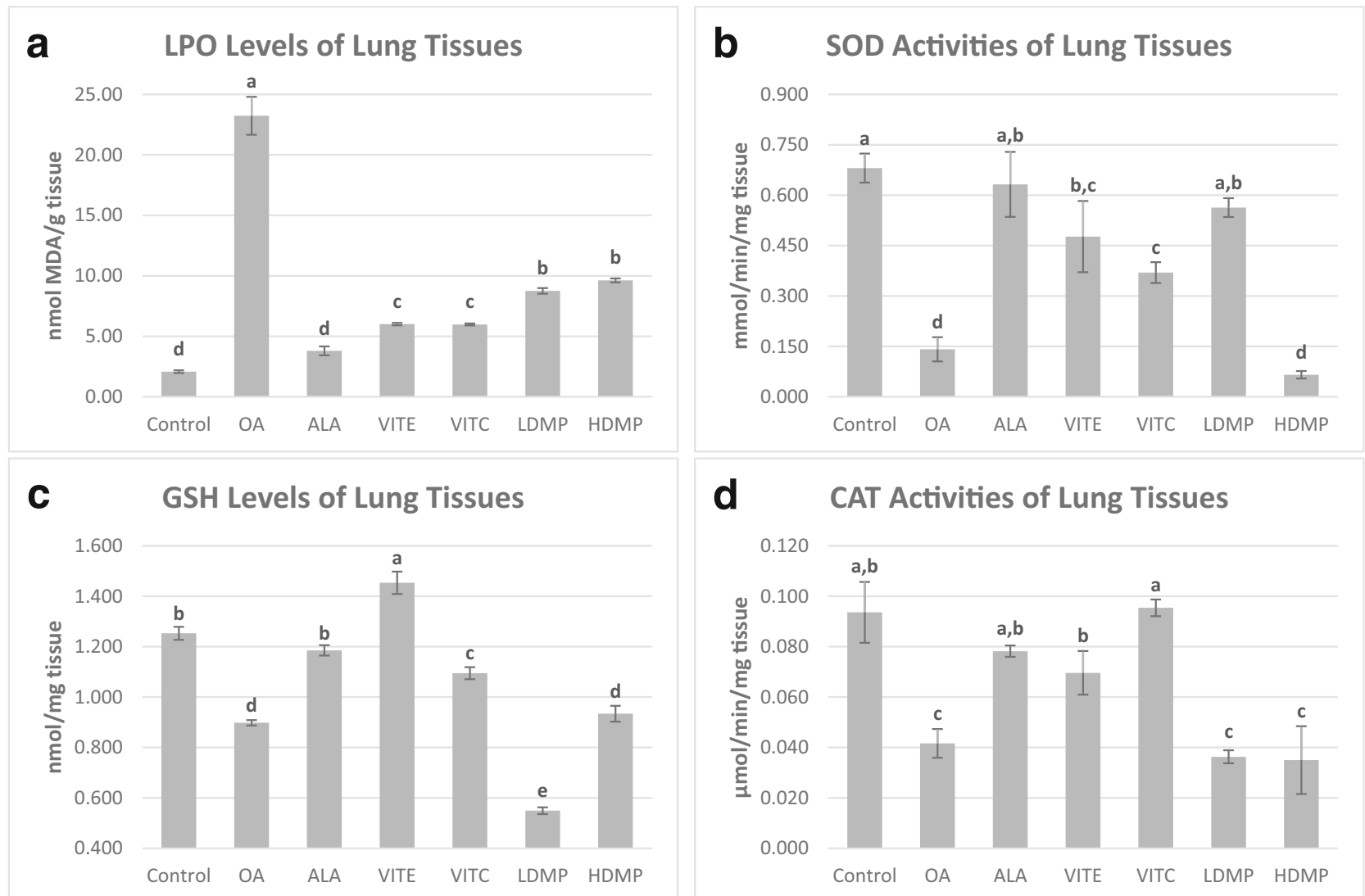

Fig. 1. Antioxidant status of lung tissues. a OA significantly increased MDA level in lung tissue compared with control group $(P<0.05)$, and all treatments markedly decreased MDA level compared with OA group $(P<0.05)$. b OA significantly decreased SOD activity in lung tissue compared with control group $(P<0.05)$. ALA, VITE, VITC, and LDMP increased SOD activity compared with OA group $(P<0.05)$. c OA markedly decreased GSH level in lung tissue compared with control group $(P<0.05)$. ALA, VITE, and VITC increased GSH level compared with OA group $(P<0.05)$. LDMP and HDMP had not any significant effect on GSH level $(P>0.05)$. d OA significantly decreased CAT activity in lung tissue $(P<0.05)$. ALA, VITE, and VITC increased CAT activity compared with OA group $(P<0.05)$. LDMP and HDMP had not any significant effect on CAT activity $(P>0.05)$. Different letters $(\mathrm{a}, \mathrm{b}, \mathrm{c}, \mathrm{d})$ indicate statistical differences between groups according to Duncan's multiple range test $(P<0.05)$ in each graphics. There is no statistically significant difference between the groups which have same letters $(P>0.05)$.

interstitial areas and moderate thickening in interalveolar areas were detected in LDMP group (Fig. 3g, Table 2). However, severe thickening in interalveolar areas, severe hyperemia in vessels, and severe mononuclear cell infiltration in interstitial and peribronchiolar areas were observed in HDMP group (Fig. 3h, Table 2).

\section{DISCUSSION}

Acute respiratory distress syndrome (ARDS), characterized by hypoxemia, pulmonary edema, diffuse endothelial damage, interstitial hemorrhage, and a strong lung inflammation, is a serious and fatal syndrome for human health. The basis of pathological changes ground on damaged pulmonary permeability barrier by edema, infiltration of inflammatory cells, exudation, and necrosis. Thus, insufficient ventilation-perfusion in lung expeditiously occurs in ARDS cases [16]. Although ARDS is thought as a pulmonary issue, it is described as a systemic inflammatory disease. ARDS also directly relates with other organ systems. Previous studies reported that inflammatory cytokines such as IL- $1 \beta$, TNF- $\alpha$, IL- 6 , and IL8 elevated in bronchoalveolar lavage fluid and blood plasma in ARDS events [24]. The inflammatory process in ARDS, characterized by releasing a cascade of variety mediators by immune-mediated cell, causes a redox imbalance that generates oxidative stress [30]. Lung alveolus is under attack by ROS and nitrogen species (RNS) in oxidative stress provided by air pollutions, inflammation, 

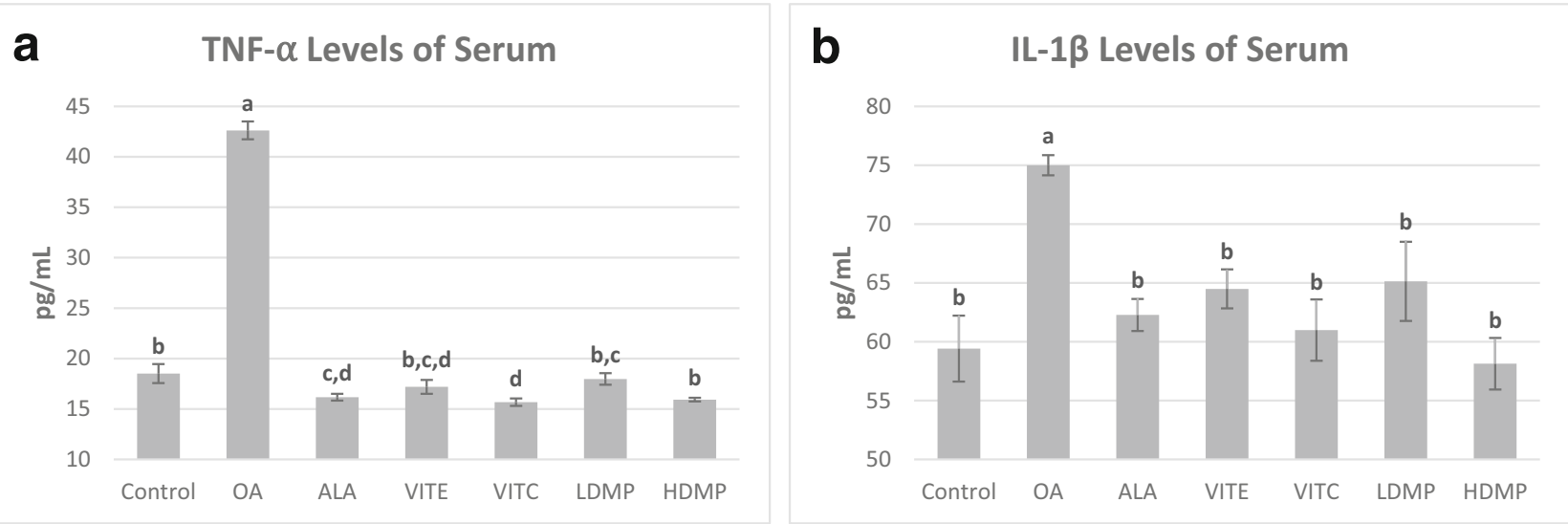

Fig. 2. TNF- $\alpha$ and IL-1 $\beta$ levels of serum. a OA significantly increased TNF- $\alpha$ level in serum compared with control group $(P<0.05)$. All treatments markedly decreased TNF- $\alpha$ level in serum compared with OA group $(P<0.05)$. b OA significantly elevated IL- $1 \beta$ level in serum compared with control group $(P<0.05)$. All treatments markedly decreased IL-1 $\beta$ level in serum compared with OA group $(P<0.05)$. Different letters $(\mathrm{a}, \mathrm{b}, \mathrm{c}, \mathrm{d})$ indicate statistical differences between groups according to Duncan's multiple range test $(P<0.05)$ in each graphics. There is no statistically significant difference between the groups which have the same letters $(P>0.05)$.

infection, and cancer. The antioxidant system of lung epithelial consists of several antioxidant molecules such as GSH, $\alpha$-tocopherol (vitamin E), ascorbic acid (vitamin C), retinol (vitamin A), and some antioxidant enzymes such as SOD, CAT, glutathione peroxidase (GPx), and reductase (GR). In normal condition, the antioxidant system of lung protects its cells from oxidative agents which are ROS and RNS via complex and coordinated interactions of the system [31]. Besides, recent studies demonstrated that ROS play an important role in mechanism of diseases $[8,17]$. Therefore, antioxidant vitamins such as ALA, VITE, and VITC are commonly used as a shield against ROS damage in most diseases. Hence, it was planned to reveal the effects of some antioxidant vitamins and methylprednisolone on acute respiratory distress syndrome rat model in present study.

Oleic acid-induced acute lung injury model is commonly used as an animal model of ARDS. Intravenously injected OA mimics pathology of ARDS and similar symptoms expeditiously occur. OA generates pulmonary vascular endothelial cell damage and causes alveo-capillary membrane degeneration, increased capillary membrane permeability and interstitial liquid, adhesion molecules production, polymorph nuclear leucocyte infiltration, activation of oxidation enzymes, cytokines releasing and increased reactive oxygen species (ROS) production $[3,6]$. Moreover, increased ROS production usually accords to neutrophil activation. The activated neutrophils increase production of superoxide and hydroxyl radicals in the tissue damage process. Meanwhile, during tissue damage process, nitric oxide is released by injured cells and activates ROS production by some reactions caused in peroxynitrite production [13]. Furthermore, previous studies reported that $\mathrm{OA}$ infusion particularly impaired the lung epithelium and endothelium, so it caused disrupted gas exchange by leaking the plasma proteins and fluid into the alveoli [14]. Likewise, in the present study, hemorrhagic areas and edema were determined around pulmonary vessels in lung tissue of OA group.

The ROS attack to unsaturated lipids of the cell membrane and generate malondialdehyde (MDA) that causes alteration in membrane structure, permeability and rigidity. The alterations in membrane are responsible for the death of cells. The tissue damage or degree of necrosis is generally observed as being parallel to MDA level of tissue. Therefore, determination of MDA level is appropriate and reliable method for showing tissue damage degree. In the present study, MDA level was found significantly increased by intravenously administered OA. Liu et al. reported that after OA injection, the level of ROS in lung tissues expeditiously increased and reached peak level in 30 min [22]. Likewise, Hshing et al. reported that serum MDA level was significantly increased by OA infusion within 30 min [10]. Yang et al. showed that infusion of increasing doses of OA markedly increased the MDA level of bronchoalveolar lavage fluid (BALF) in guinea pigs [39].

Lipoic acid is an organosulfur compound derived from octanoic acid. ALA is a strong antioxidant vitamin against to ROS and has two disulfide bonds that provide the antioxidant effects of the molecule. ALA assists to GSH regeneration by being as a source of sulfur for GSH 

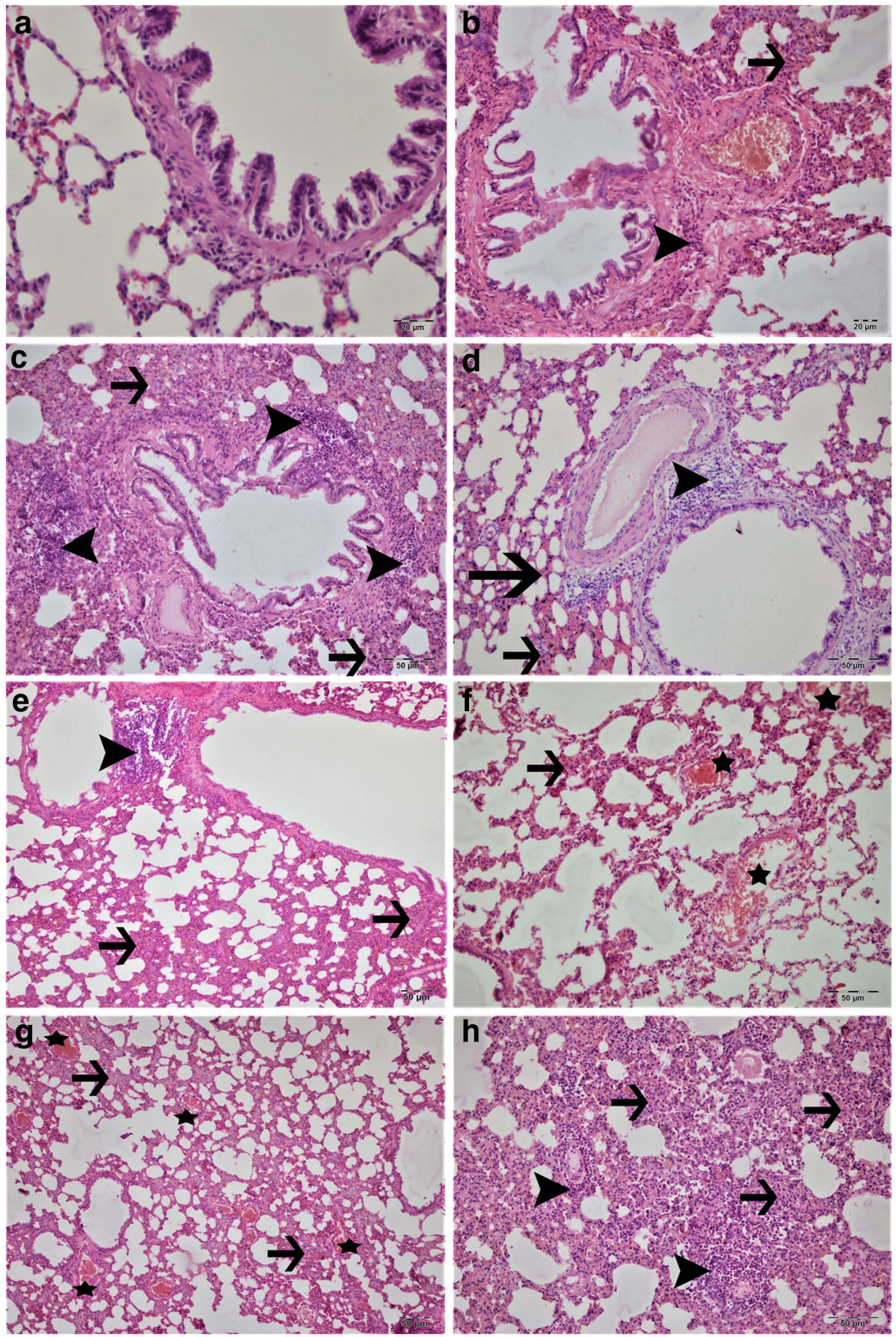

Fig. 3. Histopathological examinations of lung tissue. a Control group, normal histologic view, H\&E, $20 \mu \mathrm{m}$. b, c OA group, severe thickening in interalveolar septum (arrows), peribronchial cell infiltration, hyperemia in vessels. d ALA group, slight proliferation in interstitial areas (arrows), and mononuclear cell infiltration (arrow head). e VITE group, moderate thickening in interalveolar and interlobular septum (arrows), peribronchial mononuclear cell infiltration (arrow head). $\mathbf{f}$ VITC group, mild proliferation in interalveolar septum (arrows), hyperemia in vessels (stars). $\mathbf{g}$ LDMP group, moderate thickening in interalveoler areas (arrows), mononuclear cell infiltration in interstitial and peribronchial areas, hyperemia in vessels (stars). $\mathbf{h}$ HDMP group, severe thickening in interalveolar areas (arrow heads), mononuclear cell infiltration in interstitial and peribronchiolar areas (arrows), hyperemia in vessels (stars), H\&E. $50 \mu \mathrm{m}$. 
structure that comprises one disulfide bond [5]. ALA significantly decreased MDA level of lung tissue and there was no statistically significant difference between ALA and control groups. A previous study, which showed beneficial effects of ALA on OA induced lung injury, reported that serum MDA levels were decreased by ALA which is given before OA infusion [6].

Vitamin E (VITE) is oil-soluble compound and classified in tocopherols and tocotrienols. Also, it is known as a strong antioxidant and protector of cell membrane against oxidation reactions. Antioxidant effects of VITE are provided by hydroxyl bounded phenolic ring in the molecule structure. Moreover, VITE scavenges peroxyl radical by giving hydroxyl from the phenolic ring $[13,36]$. VITC is a water-soluble organic compound that is essential for mammalian life. It has important roles such as being cofactor and modulator of immune cells in some anabolic, catabolic, and oxidative enzyme reactions. The antioxidant power of VITC is related to its electron transport property such as transferring the unpaired electron of ROS to itself [15]. In the present study, VITC and VITE significantly decreased tissue MDA level. Likewise, Metnitz et al. reported that decreased plasma antioxidant levels such as $\alpha$-tocopherol, $\beta$-carotene, and ascorbate in ARDS patients caused increased plasma MDA levels in third and sixth days. [26].

Methylprednisolone (MP) is synthesized as a synthetic compound from organic glucocorticosteroids and hydroxycortisone by using chemical methods. MP as a synthetic corticosteroid decreases the cytokine release and inhibits activation of T cells. Therefore, MP is used against severe inflammation process such as ARDS, rheumatoid arthritis, Cushing's syndrome, etc. However, medical uses of MP may cause important adverse effects such as fluid retention, hyperglycemia, electrolyte imbalance, increased infection rate, pancreatitis, gastrointestinal bleed, neuromuscular weakness. Previous clinical trials reported that low-dose MP improved mortality and morbidity rates in ARDS cases [35], but high-dose MP did not show any effect on the rates [25]. Although LDMP and HDMP significantly decreased MDA level as in vitamin treatments, the decreasing MDA levels were not compatible to pathological findings of MP groups.

SOD enzyme uses superoxide radicals as being a substrate and catalyzes a dismutation reaction which produces hydrogen peroxide. SOD enzyme activity is directly related to antioxidant system and informs about amount of superoxide radical generation in cell. SOD inhibition causes sudden increase of superoxide radicals and elevates MDA level in tissue. The findings in present study showed that intravenously administered OA significantly inhibited
SOD activity. Likewise, previous studies reported that OA decreased SOD activity in plasma and lung tissue $[22,38]$. On the other hand, ALA, VITE, and VITC enhanced SOD activity that inhibited by OA. However, Bulmus et al. did not find any statistical differences between serum SOD activities of OA, ALA, and control groups [6]. Moreover, Yang et al. reported that SOD activity increased in broncho-alveolar lavage fluid (BALF) after intravenous administration of OA [39]. Although LDMP significantly increased SOD activity in similar to ALA, VITE, and VITC, HDMP had not any effect on SOD activity in lung tissue. Yao and Raley (1996) indicated that MP showed down-regulated SOD activity and different responses which were specific for cell type and tissue function [40].

Hydrogen peroxide $\left(\mathrm{H}_{2} \mathrm{O}_{2}\right)$ is less harmful to the cell compared with ROS, but increased $\mathrm{H}_{2} \mathrm{O}_{2}$ concentration can be dangerous for cell health and metabolism. The CAT enzyme and GSH are the important members of antioxidant system and convert the $\mathrm{H}_{2} \mathrm{O}_{2}$ to water by different mechanisms. Though CAT catalyzes an enzymatic reaction which directly uses $\mathrm{H}_{2} \mathrm{O}_{2}$, GSH is used as being a substrate for converting $\mathrm{H}_{2} \mathrm{O}_{2}$ to $\mathrm{H}_{2} \mathrm{O}$ by GR and GPx enzymes. In present study, intravenously administered OA significantly decreased GSH level and CAT activity in lung tissue. The ALA and VITE directly play a role in regeneration of the GSH from GSSG. Besides, VITC has indirect functions such as scavenging effect on ROS in regeneration of GSH [33]. On the other hand, SOD activity is an important factor for hydrogen peroxide production. Increasing $\mathrm{H}_{2} \mathrm{O}_{2}$ level depending on SOD activity elevates CAT activity as well as consumption of GSH. Although decreased SOD activity was observed, HDMP did not inhibit the GSH consumption. While SOD activity in LDMP group increased, the excessive consumption of GSH was observed. Besides, Walther (2004) reported that hydrocortisone treatment on lung cell lines decreased GSH synthesis in cells [37]. The CAT activity in lung tissue was markedly decreased by intravenously administered OA. Although ALA, VITE, and VITC showed recovery effects on CAT activities in similar to SOD activities and GSH levels, MP did not show any significant effect on CAT activity. Likewise, Bulmus et al. showed that intravenously administered OA significantly decreased serum CAT activity and $\alpha$-lipoic acid significantly increased the activity in serum [6].

In inflammation process, activated alveolar macrophages release cytokines such as tumor necrosis factor alpha (TNF- $\alpha$ ), interleukin 1 beta (IL-1 $\beta$ ), interleukin 6 (IL-6), and interleukin 8 (IL-8). In present study, while serum TNF$\alpha$ and IL-1 $\beta$ levels were increased by intravenously administered OA, administrations of ALA, VITC, VITE, LDMP, 
and HDMP decreased cytokine levels by different ways. In a previous study, Lee and Hughes (2002) reported that ALA reduced nuclear factor-kappa $\mathrm{B}(\mathrm{NF}-\mathrm{KB})$ and the releasing of cytokines which activates inflammation process was inhibited depending on the NF-KB reduction [21]. Also, Kaul et al. reported that tocopherol derives inhibited TNF$\alpha, N F-\kappa B$, and adhesion molecules which related to inflammation cells such as monocyte [20]. Bezerra et al. showed that VITC decreased inflammatory response of lung by inhibiting the TNF- $\alpha$ and NF- $\kappa B$ releases [4]. Moreover, MP caused the decreased TNF- $\alpha$ and IL- $1 \beta$ levels in serum.

Histopathologic evidences of ALA, VITE, and VITC groups showed that severe neutrophil infiltration decreased compared with OA group. Liu et al. reported that pulmonary hemorrhage, interstitial edema, inflammatory cells infiltration, and epithelium necrosis were observed after $2 \mathrm{~h}$ of OA injection [22]. In addition, less endothelial and tissue damage indicated by thickening in bronchi and alveolar septum, hyperemia in vessels and polynuclear cell infiltration were observed in histopathological evidences of the vitamin groups. However, HDMP had not significant effect on severity of mononuclear cell infiltration. Chen et al. reported that one dose methylprednisolone $(30 \mathrm{mg} / \mathrm{kg})$ intraperitoneally injection could not significantly decrease the neutrophil infiltration in a rat model of acute lung injury [9].

\section{CONCLUSION}

In conclusion, antioxidant vitamins may be useful for premedication of ARDS and similar disorders. However, MP was not found sufficient for being a therapeutic agent for ARDS. In the light of all presented findings, ARDS bases on serious inflammation process that accompanies pulmonary endothelial damage and increased ROS that are responsible oxidative damage to cells. Thus, it can be said that inhibiting the inflammation process in ARDS is not adequate for treatment and oxidative damage should be prevented by using strong antioxidants.

\section{ACKNOWLEDGEMENT}

We would like to thank Dr. Serkan Yildirim for his kindly assistance in preparing the histopathological section of the study.

\section{FUNDING INFORMATION}

This work was supported by the Ataturk University Scientific Research Unit under Grant BAP-2012/042.

\section{REFERENCES}

1. Aebi, Hugo. 1984. Catalase in vitro. Methods in Enzymology 105: 121-126.

2. Bagchi, D., A. Garg, M. Bagchi RL Krohn, M.X. Tran, and S.J. Stohs. 1997. Oxygen free radical scavenging abilities of vitamins C and $\mathrm{E}$, and a grape seed proanthocyanidin extract in vitro. Research Communications in Molecular Pathology and Pharmacology 95 (2): 179-189.

3. Beilman, Greg. 1995. Pathogenesis of oleic acid-induced lung injury in the rat: Distribution of oleic acid during injury and early endothelial cell changes. Lipids 30 (9): 817-823.

4. Bezerra, Frank Silva, Samuel Santos Valença, Manuella Lanzetti, Wagner Alves Pimenta, Paulo Castro, Vera Lúcia Gonçalves Koatz, and Luís Cristóvão Porto. 2006. $\alpha$-Tocopherol and ascorbic acid supplementation reduced acute lung inflammatory response by cigarette smoke in mouse. Nutrition 22 (11): 1192-1201.

5. Biewenga, Gerreke Ph., Guido R.M.M. Haenen, and Aalt Bast. 1997. The pharmacology of the antioxidant lipoic acid. General Pharmacology: The Vascular System 29 (3): 315-331.

6. Bulmuş, Funda Gülcü, Mehmet Ferit Gürsu, Mehmet Hamdi Muz, İhsan Yaman, Özgür Bulmuş, and Fatih Sakin. 2013. Protective effects of alpha-lipoic acid on oleic acid-induced acute lung injury in rats. Balkan Medical Journal 30 (3): 309-314.

7. Chan, Alvin C. 1993. Partners in defense, vitamin E and vitamin C. Canadian Journal of Physiology and Pharmacology 71 (9): 725 731.

8. Chapple, I.L.C. 1997. Reactive oxygen species and antioxidants in inflammatory diseases. Journal of Clinical Periodontology 24 (5): 287-296.

9. Chen, Chung-Ming, Leng-Fang Wang, Borcherng Su, and HsunHui Hsu. 2003. Methylprednisolone effects on oxygenation and histology in a rat model of acute lung injury. Pulmonary Pharmacology and Therapeutics 16 (4): 215-220.

10. Chen, Hsing I., Nan-Kuang Hsieh, Shang Jyh Kao, and Chain-Fa Su. 2008. Protective effects of propofol on acute lung injury induced by oleic acid in conscious rats. Critical Care Medicine 36 (4): 1214 1221.

11. Chen, Xin, Rhian M. Touyz, Jeong Bae Park, and Ernesto L. Schiffrin. 2001. Antioxidant effects of vitamins $\mathrm{C}$ and $\mathrm{E}$ are associated with altered activation of vascular NADPH oxidase and superoxide dismutase in stroke-prone SHR. Hypertension 38 (3): 606611.

12. Chow, Chung-Wai, Maria Teresa Herrera Abreu, Tomoko Suzuki, and Gregory P. Downey. 2003. Oxidative stress and acute lung injury. American Journal of Respiratory Cell and Molecular Biology 29 (4): 427-431.

13. Cohen, K., and A. Nyska. 2002. Oxidation of biological system: Oxidative stress phenomena, antioxidants, redox reactions and method for their quantification. Toxicologic Path 30 (6): 620-650.

14. Davidson, Kate G., Andrew D. Bersten, Heather A. Barr, Kay D. Dowling, Terence E. Nicholas, and Ian R. Doyle. 2000. Lung function, permeability, and surfactant composition in oleic acidinduced acute lung injury in rats. American Journal of PhysiologyLung Cellular and Molecular Physiology 279 (6): L1091-L1102.

15. Du, Juan, Joseph J. Cullen, and Garry R. Buettner. 2012. Ascorbic acid: Chemistry, biology and the treatment of cancer. Biochimica et Biophysica Acta (BBA) - Reviews on Cancer 1826 (2): 443-457.

16. Force, The Ards Definition Task. 2012. Acute respiratory distress syndrome: The berlin definition. JAMA 307 (23): 2526-2533. https://doi.org/10.1001/jama.2012.5669. 
17. Halliwell, Barry. 1991. Reactive oxygen species in living systems: Source, biochemistry, and role in human disease. The American Journal of Medicine 91 (3): S14-S22.

18. Halliwell, Barry, and Susanna Chirico. 1993. Lipid peroxidation: Its mechanism, measurement, and significance. The American Journal of Clinical Nutrition 57 (5): 715S-724S.

19. Herridge, Margaret S., Catherine M. Tansey, Andrea Matté, George Tomlinson, Natalia Diaz-Granados, Andrew Cooper, Cameron B. Guest, C. David Mazer, Sangeeta Mehta, and Thomas E. Stewart. 2011. Functional disability 5 years after acute respiratory distress syndrome. New England Journal of Medicine 364 (14): 1293-1304.

20. Kaul, Nalini, Sridevi Devaraj, and Ishwarlal Jialal. 2001. $\alpha$ Tocopherol and atherosclerosis. Experimental Biology and Medicine 226 (1): 5-12.

21. Lee, Heather A., and David A. Hughes. 2002. Alpha-lipoic acid modulates NF- $\mathrm{KB}$ activity in human monocytic cells by direct interaction with DNA. Experimental Gerontology 37 (2): 401-410.

22. Liu, Heliang, Deliang Zhang, Baolu Zhao, and Jinyuan Zhao. 2004. Superoxide anion, the main species of ROS in the development of ARDS induced by oleic acid. Free Radical Research 38 (12): 12811287.

23. Matthay, Michael A., Lorraine B. Ware, and Guy A. Zimmerman. 2012. The acute respiratory distress syndrome. The Journal of Clinical Investigation 122 (8): 2731-2740.

24. Meduri, G. Umberto, Djillali Annane, George P. Chrousos, Paul E. Marik, and Scott E. Sinclair. 2009. Activation and regulation of systemic inflammation in ARDS: Rationale for prolonged glucocorticoid therapy. Chest Journal 136 (6): 1631-1643.

25. Meduri, G. Umberto, A. Stacey Headley, Emmel Golden, Stephanie J. Carson, Reba A. Umberger, Tiffany Kelso, and Elizabeth A. Tolley. 1998. Effect of prolonged methylprednisolone therapy in unresolving acute respiratory distress syndrome: A randomized controlled trial. JAMA 280 (2): 159-165.

26. Metnitz, PhGH, C. Bartens, M. Fischer, P. Fridrich, H. Steltzer, and W. Druml. 1999. Antioxidant status in patients with acute respiratory distress syndrome. Intensive Care Medicine 25 (2): 180-185.

27. Nagel, E, zu Vilsendorf A Meyer, M Bartels, and R Pichlmayr. 1996. Antioxidative vitamins in prevention of ischemia/reperfusion injury. International journal for vitamin and nutrition research. Internationale Zeitschrift fur Vitamin-und Ernahrungsforschung. Journal international de vitaminologie et de nutrition 67 (5):298-306.

28. Niki, Etsuo, Yorihiro Yamamoto, Erika Komuro, and Keizo Sato. 1991. Membrane damage due to lipid oxidation. The American Journal of Clinical Nutrition 53 (1): 201S-205S.
29. Ohkawa, Hiroshi, Nobuko Ohishi, and Kunio Yagi. 1979. Assay for lipid peroxides in animal tissues by thiobarbituric acid reaction. Analytical Biochemistry 95 (2): 351-358.

30. Pierrakos, Charalampos, Menelaos Karanikolas, Sabino Scolletta, Vasilios Karamouzos, and Dimitrios Velissaris. 2012. Acute respiratory distress syndrome: Pathophysiology and therapeutic options. Journal of Clinical Medicine Research 4 (1): 7-16.

31. Schmidt, R., T. Luboeinski, P. Markart, C. Ruppert, C. Daum, F. Grimminger, W. Seeger, and A. Günther. 2004. Alveolar antioxidant status in patients with acute respiratory distress syndrome. European Respiratory Journal 24 (6): 994-999.

32. Sedlak, Jozef, and Raymond H. Lindsay. 1968. Estimation of total, protein-bound, and nonprotein sulfhydryl groups in tissue with Ellman's reagent. Analytical Biochemistry 25: 192-205.

33. Sies, Helmut, and Wilhelm Stahl. 1995. Vitamins E and C, betacarotene, and other carotenoids as antioxidants. The American Journal of Clinical Nutrition 62 (6): 1315S-1321S.

34. Sun, Y.I., Larry W. Oberley, and Ying Li. 1988. A simple method for clinical assay of superoxide dismutase. Clinical Chemistry 34 (3): 497-500.

35. Tang, Benjamin M.P., Jonathan C. Craig, Guy D. Eslick, Ian Seppelt, and Anthony S. McLean. 2009. Use of corticosteroids in acute lung injury and acute respiratory distress syndrome: A systematic review and meta-analysis. Critical Care Medicine 37 (5): 1594 1603.

36. Traber, Maret G., and Jeffrey Atkinson. 2007. Vitamin E, antioxidant and nothing more. Free Radical Biology and Medicine 43 (1): 4-15.

37. Walther, Udo I. 2004. Changes in the glutathione system of lung cell lines after treatment with hydrocortisone. Archives of Toxicology 78 (7): 402-409.

38. Wang, Cong, H.Y. Wang, Z.W. Liu, Yan Fu, and Bin Zhao. 2011. Effect of endogenous hydrogen sulfide on oxidative stress in oleic acid-induced acute lung injury in rats. Chinese Medical Journal 124 (21): 3476-3480.

39. Yang, Changqing, Hiroshi Moriuchi, Junko Takase, Yoichi Ishitsuka, Mitsuru Irikura, and Tetsumi Irie. 2003. Oxidative stress in early stage of acute lung injury induced with oleic acid in Guinea pigs. Biological and Pharmaceutical Bulletin 26 (4): 424-428.

40. Yao, Xiaofei, and Kyle E. Rarey. 1996. Detection and regulation of $\mathrm{cu} / \mathrm{Zn}-\mathrm{SOD}$ and Mn-SOD in rat cochlear tissues. Hearing Research 96 (1): 199-203.

Publisher's Note Springer Nature remains neutral with regard to jurisdictional claims in published maps and institutional affiliations. 